statistics as an injury death, due to under-reporting and misclassification. Both factors varied by external cause, with homicides accounting for $42 \%$ of missing deaths, and transport injuries, another $14 \%$, while under-reporting was $32 \%$ and $26 \%$ respectively. Together, they accounted for $56 \%$ of all missing deaths. Although actual numbers were smaller, under-reporting losses were $43 \%$ for self-harm, $50 \%$ for fire/flames, $78 \%$ for drowning and $80 \%$ for falls. Misclassification of reported injury deaths, further exacerbated the situation, particularly underestimating homicides, $6.8 \%$ of which had been reported as accidental firearm injuries.

Conclusions Incorporating data from sources other than vital registration identified more than $900( \pm 200)$ additional fatal injuries in a mortality database of 19300 , As approximately 500 of these were homicides, it placed the latter on par with diabetes and second only to cerebrovascular disease, with grave implications for priority setting in health policy and planning.

\section{THE VALUE OF MULTI-SOURCE DATA HARVESTING FOR INJURY MORTALITY DATA: THE JAMAICAN EXPERIENCE}

doi:10.1136/injuryprev-2012-040580g.29

${ }^{1} Y$ Holder*, ${ }^{2}$ A McCaw-Binns. ${ }^{1}$ International Biostatistics \& Information Services, Saint Lucia; ${ }^{2}$ Department of Community Health, University of the West Indies, Jamaica

Background Under-reporting of fatal injuries, especially homicides is common to many Lower and Middle Income Countries and challenges the utility of injury mortality data. Since an evaluation of the vital registration system in 1998, Jamaica has instituted several improvements.

Aim This evaluation of 2008 mortality data assessed coverage of the vital registration system and quality of the data generated.

Methodology Data from the national vital registration system was complemented by data from hospital medical records, pathology reports, and police reports for fatal events for 2008. A 1-in-10 systematic sample was drawn and with the additional data gleaned from all sources, the cause of death was recoded, if warranted.

Results From the sample, more than one in four fatal injuries $(29.3 \%)$ was not reported in the year's official mortality 